\title{
Development of mobile robot for measuring distance using optical quadrature encoder
}

\author{
Madiha Zahari ${ }^{1}$, NurliyanaAbd Mutalib ${ }^{2}$, Nurnadia Natasya Affendi ${ }^{3}$, Hashim $^{4}$, DA Hadi ${ }^{5}$, \\ Siti Halma Johari ${ }^{6}$, N. Ab Wahab ${ }^{7}$, Suziana Ahmad \\ 1,2,3,4,5,6,8 Faculty of Electrical \& Electronic Engineering Technology, Universiti Teknikal Malaysia Melaka, Malaysia \\ ${ }^{7}$ Faculty of Mechanical \& Manufacturing Engineering Technology, Universiti Teknikal Malaysia Melaka, Malaysia
}

\section{Article Info}

Article history:

Received Sep 10, 2019

Revised Nov 14, 2019

Accepted Nov 28, 2019

Keywords:

Mobile robot

Robot measuring system

\begin{abstract}
This paper describes the design and development of a measuring tool using a mobile robot. At present, contractors are measuring distances using measuring tape which has few limitations. This includes using of another manpower or a marking flag. The Robot Measuring System is designed to measure distances at multiple conditions such as smooth and rough surface. An optical quadrature encoder is used as a sensor to measure the distances while a program is installed in Arduino Uno for reading and data collection. Graphical User Interface (GUI) was created using Android software so that the movement of the robot can be controlled using a smartphone within a Bluetooth range. An experiment was conducted to test the reliability in terms of accuracy and precision. The best accuracy and precision were obtained when the robot speed is at $90 \mathrm{~cm} / \mathrm{s}$ on the plain tiles, $80 \mathrm{~cm} / \mathrm{s}$ on the tar road and $90 \mathrm{~cm} / \mathrm{s}$ on the grass surface. The robot speed needs to be adjusted accordingly based on the surfaces in order to get an accurate result. This paper proved that the robot measuring system was successfully designed, implemented and analyzed.
\end{abstract}

Copyright $(2020$ Institute of Advanced Engineering and Science. All rights reserved.

\section{Corresponding Author:}

Madiha Zahari,

Faculty of Electrical \& Electronic Engineering Technology,

Universiti Teknikal Malaysia Melaka,

Hang Tuah Jaya, 76100 Durian Tunggal, Melaka, Malaysia.

Email: madiha@utem.edu.my

\section{INTRODUCTION}

In recent year, developments of mobile robot have been popular in research field. The authors in [1-3] have been developed mobile robot for various applications. Measuring of distance between one point to another point still using conventional measuring method which still using of measuring tape. Conventional measuring tool is produced using a metal strip with straight estimation markings. This type of measuring tool is often stiff, and require extra manpower or a marking flag to complete the measuring tasks especially for long distances. This paper focused on the design and development of a measuring tool using a wheel robot. The designed wheel robot is able to improve the existing conventional measuring tool. It capable to measure displacement which is length and width using a microcontroller and to provide an accurate measurement.

The author in [4] had developed an onmi-directional distance sensors and mecanum wheels. The robot measures environment situation such as distance between the side walls and mobile robots. Data National Instrument (DaNI) mobile robot was developed by [5] where this robot consists of three flat wheel terrains for localizations. The localizations were used to associate environment data captured by the robot with the location where this data is captured, or to issue robot commands depending on location and remaining battery energy. A new algorithm proposed in [6] for improving estimation accuracy of travel 
distance of a mobile robot by estimating the slanted angle of the road. They used six wheels with encoder to estimate the travel distance while gyroscopic sensor is used to estimate the slope of travelling road.

A mobile robot needs to be equipped with appropriate and suitable sensors so that a safe and effective path can be found. Kuester [7] are using laser displacement sensor while modelling the wind tunnel position measurement and conclude that the length output from the lasers was found to drift slightly with temperature. Laser displacement sensor has been used in [8-11] which conclude that the measurement using this method provide more convenient operation and ease to be used. A study conducted in [12] proposed to use light emitting diode reflective distance sensors (LED-RDS) for displacement measurement which is cheaper and inherently safe alternative to sensors using lasers and optical fibers. According to [13-15], by applying multiple sensor in measuring system, high precision and more accurate distance information is obtained. Work in [16] mentioned many indoor robotics systems utilize laser rangefinders as their essential sensor for mapping, localization, and obstacle avoidance. However the cost and power energy of such systems is a major roadblock to the deployment mobile robot.

An odometer or encoder is one of the oldest and basic techniques. The optical quadrature encoders are connected to the shaft between the motors and the wheels [2]. According to [17-19], the encoder is the most fundamental method used for localization of mobile robots using wheel encoders. It uses periodic information on velocity and distance travelled to estimate the current robot pose. There are several advantages of optical quadrature encoder which is good for frequency monitoring applications and also for speed, bearing and position observing. Brugnano [20] proposed to use encoder in measuring speed since this method is cost effective and However, the issues of ensuring of mobile robot control systems to have an effective control and security, require further research and development [21]. Previous work by [22-23] controlled their mobile robot using internet of things which able to monitor the robot in real time. However, this method is more complex which is not suitable to use in measuring system. Study by [24-25] reported that by control of mobile robot through Bluetooth using Arduino platform is much cheaper and more convenient to be cormecialized. Compared to the previous work, this paper presents the design and development of a robot measuring system controlled by a smartphone using two optical quadrature encoders attached to the front wheels.

\section{RESEARCH METHOD}

In order to choose the wheel of the robot, the size \& tread of the wheel, the sensor and the direct current (DC) motor must be chosen correctly in order to make sure the robot is able to perform it tasks. Figure 1 shows the wheel, sensor and DC motor used in this work. The chosen wheel is capable to run on smooth or rough surface area. The size of the chosen wheel robot is $65 \mathrm{~mm} \times 27 \mathrm{~mm}$ while the encoder has twenty holes with size $26 \mathrm{~mm}$.

DC gear motor is used as mechanical gears to reduce the speed or increase the torque of the motor. L298 Dual Motor Controller Module enables to control the speed and direction of two DC motor easily. It has the operating voltages between 5 to 35 Volts. This motor driver is used with motors that have a voltage of between 5 and $35 \mathrm{~V}$ DC.

An Inertial Measurement Unit (IMU) is an electronic that combine with several sensor which is accelerometer, gyroscope and magnetometer that measure and report specific force, angular rate and sometimes the magnetic field surrounding the body. Figure 2 shows the block diagram of the system designed. The designed robot has four wheels as mobility but only two front wheels are attached to DC motor and optical quadrature encoder module.

On the software development part, the Arduino Uno board has been chosen because it is more practical and able to sense environment surrounding by using different transducers. The coding was drafted using $\mathrm{C}$ language before being combined with the designed hardware. The connections between sensor and motor with Arduino were established. A GUI was created in Android smartphone so that users can easily control all the movement of the mobile robot. Users can easily explore the system without knowing the complexity of software actions behind it. 


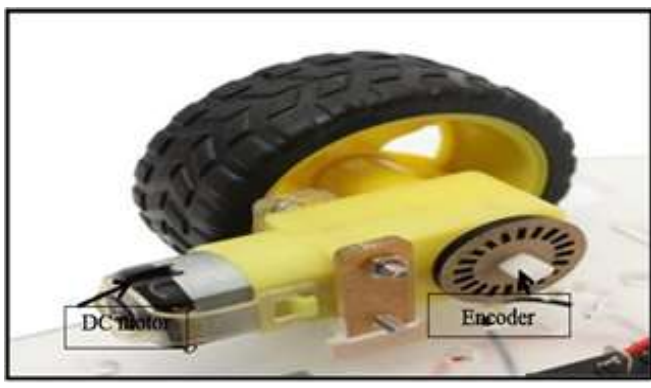

Figure 1. Robot wheel, DC motor and encoder

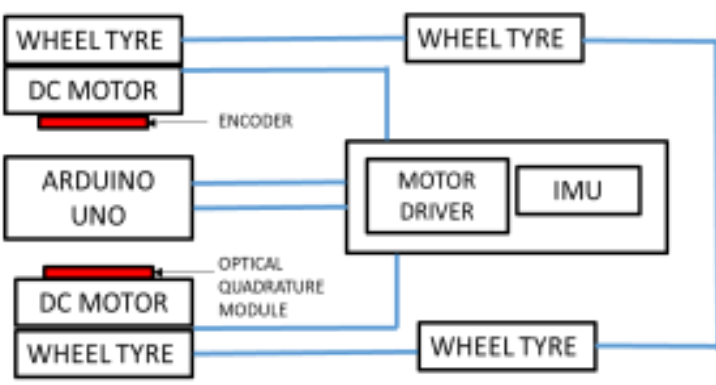

Figure 2. System block diagram of measuring robot

\section{RESULTS AND ANALYSIS}

In The overall view of the designed robot shows in Figure 3. The body of the robot was made from solid transparent plastic known as Perspex and the hardware includes motor driver L298N for the movement of the robot, optical encoder module for counting the distances, two DC Gear Motor, four wheel robot, two encoders, LCD display, two battery holders with 9 Volts battery each, on and off switch, Bluetooth transmitter HS-05 and Arduino Uno module.

The encoder will start to count when the right side of the wheel with the encoder rotates on the optical encoder module. The distance will depend on the how many encoder rotates on the optical encoder module. When the sensor detects black and white encoder, it will count one centimeter $(1 \mathrm{~cm})$. After that, the value will convert and display on the LCD display.

Figure 4 shows the Graphical User Interface (GUI) display in Android smartphone. Massachusetts Institute of Technology (MIT) App Inventor is used to create the GUI for Android working framework. MIT Application Inventor for Android is an open-source web application initially gave by Google, and now kept up by the Massachusetts Institute of Technology (MIT). By using the GUI, user able to control the movement of the robot using Android smartphone within Bluetooth range. There are five buttons to control the movement of the mobile robot, one button to scan for Bluetooth range and another button to disconnect from the Bluetooth connection.

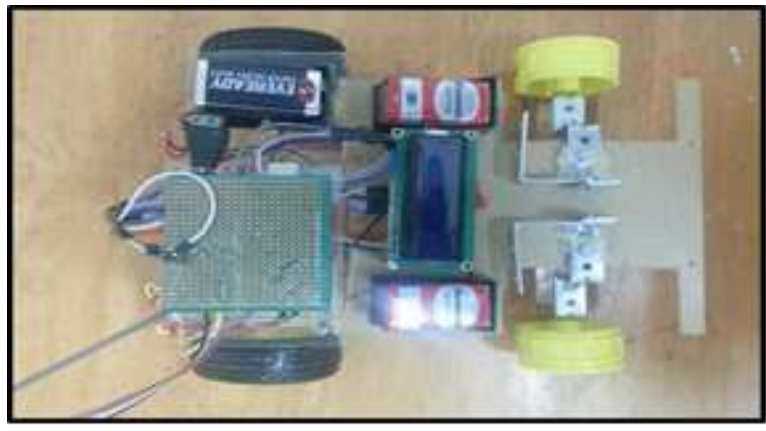

Figure 3. Top view of robot measuring system

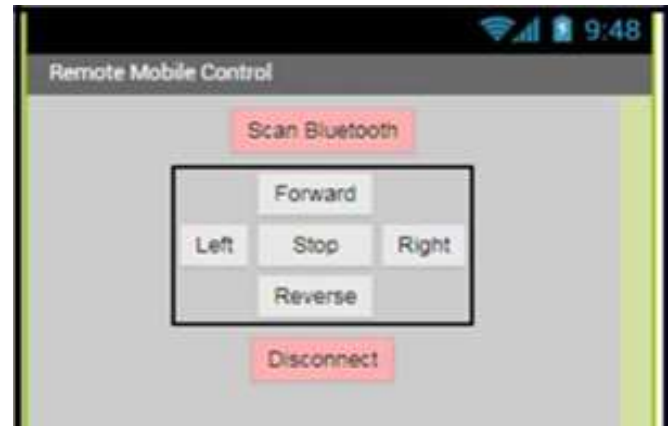

Figure 4. GUI in Android smartphone

An experiment was conducted to test the reliability of the system designed in terms of accuracy and precision. The measuring mobile robot has been tested for three different condition surfaces. The three surfaces are plain tiles, tar and grass with three different speeds which are 70,80 and $90 \mathrm{~cm} / \mathrm{s}$. Testing has been done for 30 times in order to get average (mean), minimum and maximum for the value of distance. Table 1 shows the average value for distance measured using the mobile robot. Then, accuracy and precision will be calculated. Figure 5 shows the percentage of accuracy of mobile robot in three different speed. From Figure 5 it shows that the best accuracy was obtained when the robot speed is at $80 \mathrm{~cm} / \mathrm{s}$ at tar surface, $90 \mathrm{~cm} / \mathrm{s}$ on the plain tiles and grass surface. With the results, it can be concluded that the robot speed needs to be adjusted accordingly based on the surfaces in order to get accurate reading. However, to optimize the usage of the mobile robot, $90 \mathrm{~cm} / \mathrm{s}$ is the best speed setting in all surface. 


\begin{tabular}{ccccc} 
Table 1. Average value for Distance Measured using Mobile Robot \\
\cline { 2 - 5 } & Surface & \multicolumn{2}{c}{ Speed } & \multicolumn{2}{c}{ Data Measured using Robot $(\mathrm{m})$} \\
Types & $(\mathrm{cm} / \mathrm{sec})$ & 1 meter & 2 meter & 3 meter \\
\hline TILE & 70 & 0.968 & 1.968 & 2.943 \\
& 80 & 0.989 & 1.856 & 2.767 \\
& 90 & 0.994 & 1.968 & 2.994 \\
TAR & 70 & 1.083 & 2.015 & 3.01 \\
& 80 & 1.011 & 2.01 & 3.005 \\
& 90 & 1.018 & 2.02 & 3.015 \\
GRASS & 70 & 0.963 & 1.978 & 2.97 \\
& 80 & 0.971 & 1.972 & 2.967 \\
& 90 & 0.98 & 1.995 & 2.975 \\
\hline
\end{tabular}

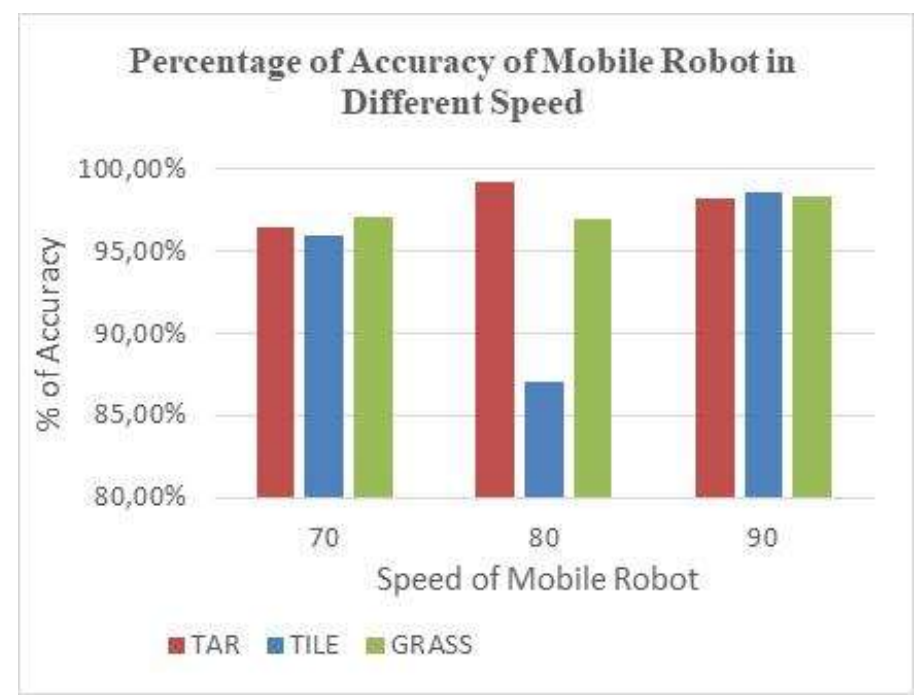

Figure 5. Percentage of accuracy for different speed and different surface

\section{CONCLUSION}

A robot measuring system has been designed, developed and tested successfully. Through this study, the designed system were tested at three different areas. Robot measuring system is ready to be used to replace the conventional measuring system. In the future, the Bluetooth system can be replaced with Wireless Fidelity (WiFi) system to increase the measuring coverage.

\section{ACKNOWLEDGEMENTS}

This work was partially supported by Universiti Teknikal Malaysia Melaka (UTeM) and the Malaysia Ministry of Higher Education for the financial funding under Grant No. PJP/2018/FTK(1B)/S01580

\section{REFERENCES}

[1] Tauwafak, M.A., Alaraji, A.S., Sadiq, B.R. Development of aFree-Navigation Mobile Robot System Based on a Digital Image Processing Methodology, IOP Conference Series: Materials Science and Engineering. 2018.

[2] Cartal, L.A., Gheorghe, V.I., Rotaru, A., Duminică, D., Petrache, S. Developing a new mobile robotic structure for search and rescue operations. IOP Conference Series: Materials Science and Engineering, 2018; 444 (4). DOI: 10.1088/1757-899X/444/4/042016

[3] Bisi, S., De Luca, L., Shrestha, B., Yang, Z., Gandhi, V. Development of an EMG-controlled mobile Robot, Robotics, 2018; 7 (3), art. no. 36. DOI: 10.3390/robotics7030036

[4] Chu, B. "Mobile robot position control algorithm based on multiple ultrasonic distance." Proceedings of IEEE International Conference on Control, Automation and Systems (ICCAS) 2015. 2015. 2093-7121

[5] Sibai, F. N., Trigui, H.,Zanini, P.C., Al-Odail, A. R. 2012. "Evaluation of indoor mobile robot localization techniques." Proceedings of Computer Systems and Industrial Informatics (ICCSII) 2012.

[6] Kim, K. et al., 2012. "Improvement of Travel Distance at the Outdoor Environment by using IMU and Encoder." 2012 12th International Conference on Control, Automation and Systems, 1, pp.1669-1674. 
[7] Kuester, M., Intaratep, N., Borgoltz, A. Laser Displacement Sensors for Wind Tunnel Model Position Measurements (2018) Sensors (Basel, Switzerland), 18 (12). DOI: 10.3390/s18124085

[8] Wang, L., Yang, F., Fu, L., Wang, Z., Yang, T., Liu, C. A fast measuring method for the inner diameter of coaxial holes (2017) Sensors (Switzerland), 17 (3), art. no. 652. DOI: 10.3390/s17030652

[9] T. Li, Z. Xing and S. Chen, "An online wheel size detecting technology based on laser displacement sensors for urban rail vehicles, " 2017 36th Chinese Control Conference (CCC), Dalian, 2017, pp. 9983-9987.

[10] B. Sun and B. Li, "Laser Displacement Sensor in the Application of Aero-Engine Blade Measurement," in IEEE Sensors Journal, 2016, March, vol. 16, no. 5, pp. 1377-1384.

[11] P. Giri and S. Kharkovsky, "Detection of Surface Crack in Concrete Using Measurement Technique With Laser Displacement Sensor," in IEEE Transactions on Instrumentation and Measurement, vol. 65, no. 8, pp. 1951-1953, Aug. 2016.

[12] Khubchandani, S., Hodkiewicz, M.R., Keating, A. Characterizing the Performance of LED Reflective Distance Sensors (2017) IEEE Access, 5, art. no. 7990492, pp. 14289-14297. DOI: 10.1109/ACCESS.2017.2731801

[13] Yong, Q., Jing, H., Lijie, W. Measuring system for mobile robot based on multiple sensors. Proceedings of 2011 International Conference on Electronic and Mechanical Engineering and Information Technology, EMEIT 2011, 2 , art. no. 6023259, pp. 980-983. DOI: 10.1109/EMEIT.2011.6023259

[14] Nong, X., Cheng, L., Yating, D., Rui, P., Chen, Y., Wu, H. Research on indoor navigation of mobile robot based on INS and ultrosound. Proceedings of the 2017 12th IEEE Conference on Industrial Electronics and Applications, ICIEA 2017, 2018 February, pp. 231-235. DOI: 10.1109/ICIEA.2017.8282848

[15] Lin, Y., Huang, Y., Shi, E. Application of data fusion algorithm based on Kalman filter in mobile robot position measuring system. Proceedings of the World Congress on Intelligent Control and Automation (WCICA), 2004, 6.

[16] Konolige, K. et al., "A Low-Cost Laser Distance Sensor” 2008; pp.3002-3008.

[17] Mahmud, A. et al., "Kalman Filter based Indoor Mobile Robot Navigation.”, 2016; pp.1949-1953X.

[18] Petrella, R., Tursini, M.An embedded system for position and speed measurement adopting incremental encoders. IEEE Transactions on Industry Applications, 2008; 44 (5), pp. 1436-1444. DOI: 10.1109/TIA.2008.2002167

[19] Merry, R.J.E., van de Molengraft, M.J.G., Steinbuch, M.Velocity and acceleration estimation for optical incremental encoders. Mechatronics, 2010; 20 (1), pp. 20-26. DOI: 10.1016/j.mechatronics.2009.06.010

[20] Brugnano, F., Concari, C., Imamovic, E., Savi, F., Toscani, A., Zanichelli, R. A simple and accurate algorithm for speed measurement in electric drives using incremental encoder. Proceedings IECON 2017-43rd Annual conference of the IEEE Industrial Electronics Society, 2017-January, pp. 8551-8556. DOI: 10.1109/IECON.2017.8217502

[21] Parkhomenko, A., Kravchenko, D., Kravchenko, O., Gladkova, O. Hybrid control system of mobile objects for IoT. Dependable IoT for Human and Industry: Modeling, Architecting, Implementation, 2018.

[22] Kavya, K.V., Suresh, K.S., Umamakeswari, A.A telepresence mobile robot controlling and real time detection using internet of things. Indian Journal of Science and Technology, 2016; 9 (48). DOI: 10.17485/ijst/2016/v9i48/108008

[23] Vanitha, M., Selvalakshmi, M., Selvarasu, R.Monitoring and controlling of mobile robot via internet through raspberry Pi board, 2016, pp. 462-466. DOI: 10.1109/ICONSTEM.2016.756086

[24] Singh, V.K., Sahu, A., Beg, A., Khan, B., Kumar, S. Speed Direction Control of DC Motor through Bluetooth HC05 Using Arduino, 2018 art. no. 8933698, DOI: 10.1109/ICACAT.2018.8933698

[25] Shimpi, Mayuresh, "Speed Control of DC Motor Using Bluetooth Devices." International Journal for Research in Applied Science and Engineering Technology. 2018, 6. 2664-2670. 10.22214/ijraset.2018.3430. 